\title{
GÉNESIS Y COMPOSICIÓN DE UN SISTEMA MIGRATORIO IBEROAMERICANO
}

\author{
Fernando Osvaldo Esteban ${ }^{1}$ \\ Universidad de Buenos Aires - CONICET, Argentina
}

Resumen.- El artículo explora la existencia de un sistema migratorio integrado por países latinoamericanos y caribeños, como centros emisores de población, y España como polo receptor. El análisis se ha realizad, desde una perspectiva cuantitativa, mediante la explotación de diversas fuentes estadísticas disponibles. La evidencia empírica ha confirmado la existencia de un sistema migratorio constituido por España, como el polo receptor más importante y varios países de Sudamérica como emisores principales de población: Ecuador, Colombia, Bolivia y Argentina. Actualmente, estaría ampliándose a países centroamericanos. Entra las características más significativas debe destacarse que los flujos migratorios son de carácter económico, presentan elevados índices de feminización y se han insertado en las categorías ocupacionales más bajas. Este sistema se ha desarrollado en la última década pero ya encontraba constituido de forma embrionaria desde la década de 1970 con una composición diferente: estaba integrado sobre todo por exiliados de las dictaduras del Cono Sur.

Palabras clave.- sistema migratorio, Latinoamérica, España

Abstract.- The article explores the existence of a Latin-American \& Caribbean - Spain migratory system. Latin American and Caribbean is the immigrants' region of origin, and Spain is the host society. The data analysis has been developed using statistical methods or tools. The empirical evidence has confirmed the existence of a migratory system. Spain is the receiving center and several South America countries the major emigration region (Ecuador, Colombia, Bolivia and Argentina). However, migratory system has been able to include Central American countries in last years. We identify some relevant characteristics about this migratory system: the migratory flows are economic, present high index of feminisation and the labour market insertion occurs in the lowest level of the labour market. This system has been developed in the last decade but it was constituted in the early 1970s (of an embryonic form). It presented a different composition: it was integrated mainly by Southern Cone exiled

Key words.- Migration System, Latin-America migration, Spain immigration

\section{La reciente emigración internacional en América Latina y el Caribe}

Los desplazamientos de población desde y dentro de Latinoamérica y el Caribe se han incrementado aceleradamente en las últimas décadas. De acuerdo a la División de Población de la CEPAL (Martínez Pizarro, 2008:86), el número de migrantes latinoamericanos y caribeños ha aumentado de un total estimado en más de 21 millones de personas en 2000 a casi 26 millones en 2005. Una tendencia que se inscribe en otras de mayor escala a nivel mundial (Ver Naciones Unidas, 2008).

\footnotetext{
${ }^{1}$ CONICET (UBA). Centro Redes.
} 
En las dos décadas que van desde 1960 a 1980, la mayor parte de los países de la región sufrieron inestabilidad política, violentas dictaduras y en algunos países centroamericanos, cruentas guerras civiles, dando origen a masivas oleadas migratorias de exiliados y refugiados políticos. Una vez consolidados los regímenes democráticos durante el decenio de 1990, las migraciones internacionales continuaron pero esta vez debido a motivos económicos. El volumen de migrantes creció paulatinamente y los desplazamientos se volvieron sistemáticos. Según estimaciones de la CEPAL, cerca de la mitad del stock actual de emigrantes salió de su país de nacimiento en el decenio de 1990.

Entender este proceso merecería abordar cuestiones que, por motivos de espacio, no podemos desarrollar aquí, pero que al menos es necesario apuntar. Los estudios demuestran que el origen, dirección y magnitud de estos flujos migratorios obedecen tanto a factores económicos estructurales como coyunturales de las sociedades involucradas (Solimano, 2003; Pellegrino, 2003; Martínez Pizarro, 2004 y 2008) y a otros que a nivel micro responden a estrategias y situaciones de individuos y sus familias (Pellegrino, 2004).

Desde una perspectiva estructural, los desplazamientos se generaron por las brechas históricas de desarrollo "Norte y el Sur", y entre los propios países fronterizos de la región, conjuntamente con la frecuencia de ciclos económicos en forma de crisis de crecimiento. Habría que destacar en este sentido que la concurrencia paradójica entre emigración internacional, democracia y crisis económica en América Latina se produjo en las últimas décadas bajo "el signo del neoliberalismo" (Weyland, 2004). Ello nos remite indefectiblemente, más allá de las asimetrías nacionales, al desmantelamiento del modelo de desarrollo económico basado en la industrialización sustitutiva de importaciones vigente desde la postguerra, y su correlato social, un modelo "nacional- popular" de Estado Social, sucedáneo imperfecto y disfuncional del Estado de Bienestar?

Al nivel de los propios actores, esta transformación radical de las sociedades latinoamericanas que supuso el fin de la estrategia de industrializadora contribuyó, básicamente, de dos maneras a incrementar la emigración internacional: desde un punto de vista objetivo, produciendo un deterioro aún más profundo de la cohesión social, que de por sí era parcial en la región, mediante el incremento de la desigualdad, la pobreza, la indigencia y la precarización del mundo del trabajo (caída del salario real, informalidad, desempleo, temporalidad.... $)^{3}$. De esta manera se evacuaron rápidamente las expectativas de progreso que había condensado la recuperación de la democracia. Desde un punto de vista subjetivo, porque el neoliberalismo produjo un gran proceso de descolectivización (Castel, 1999) que condujo a

\footnotetext{
${ }^{2}$ Marcelo Cavarozzi (1992), desde la perspectiva de la economía política, ha utilizado la expresión "matriz estado céntrica" para describir la relación predominante entre Estado y economía en un modelo de desarrollo "orientado hacia adentro". El origen de la expresión nacional - popular se puede atribuir a Gino Germani (1978). Alain Touraine (1989) también utiliza este concepto.

${ }^{3}$ Para más detalles ver PNUD, 2004
} 
nuevas estrategias de movilidad (social y geográfica), más individuales pero al mismo tiempo asociadas a pautas de consumo globalizadas ${ }^{4}$.

La migración extra-regional de latinoamericanos y caribeños es un patrón de migración "Sur-Norte" que continúa teniendo a Estados Unidos como el principal receptor, pero que en la última década ha ido diversificando y ampliando la geografía de destinos. Actualmente, este proceso constituye uno de los signos de identidad de esta movilidad. España, junto con Japón, Canadá, Australia e Israel se constituyeron en los destinos más dinámicos durante la última década (Martínez Pizarro, 2008).

Hasta el momento la literatura especializada no ha profundizado en las causas que impulsaron la ampliación del mapa de destinos de la emigración internacional de latinoamericanos, aunque sí han señalado algunos factores intervinientes como la demanda de trabajadores en los países receptores, ya sea por motivos demográficos (envejecimiento de la población autóctona) o porque los nuevos empleos son considerados "indeseables" por los trabajadores locales; el accionar de las redes sociales, sobre todo a partir de la extensión de las TIC (Tecnologías de la Información y la Comunicación); y los vínculos históricos que ligan a los países (y las regiones) de origen con los de destino.

Sobre la base de los dos últimos puntos, investigaciones recientes (Actis, 2009; Maguid y Martínez, 2008, Actis y Esteban, 2007) señalaron que probablemente se haya constituido un nuevo sistema migratorio "Sur - Norte" en la última década, donde España sería el principal país receptor, junto a otros europeos, y varios países de Latinoamérica y el Caribe los emisores principales de migrantes. Se trata de una explicación novedosa de las actuales migraciones extra-regionales de latinoamericanos y caribeños, pero aún insuficientemente discutida.

El objetivo de esta investigación es comprobar a partir de la evidencia empírica disponible si se ha constituido este nuevo sistema migratorio y, de ser así, describir su génesis y composición para el caso España. Antes de presentar los datos, abordamos los principios fundamentales de la teoría de sistemas migratorios.

\section{El enfoque de sistemas en la teoría migratoria: una síntesis}

A partir de la contribución de Akin Mobogunje (1970) en su estudio sobre la migración rural - urbana en África, el enfoque de sistemas se ha propuesto como un enfoque completo para el estudio de las migraciones. En aquel trabajo, Mobogunje (1970: 16) sostuvo que la migración rural - urbana podría ser estudiada a partir de un enfoque sistémico con el objetivo de capturar el impacto espacial y el rol de la migración en las transformaciones de las estructuras económicas y sociales de ambas áreas.

\footnotetext{
${ }^{4}$ Ver García Canclini (1994): introducción y capítulo I.
} 
La base de este punto de vista es el concepto de sistema migratorio: espacios caracterizados por la asociación relativamente estable de una serie de países receptores, con un número determinado de regiones de origen (Kritz, Zlotnik, 1992:2). Tal como sostienen las teorías del sistema mundial, de las redes sociales, institucional y de la causación acumulativa, tales asociaciones no son mero resultado de las corrientes migratorias sino que se ven reforzadas por conexiones y vínculos de distinta naturaleza: personas, bienes, capital, cultura, etc.. Cada uno de dichos sistemas posee una región receptora central, constituida por uno o varios países, y un conjunto de países emisores relacionados a este núcleo mediante voluminosos flujos migratorios (Massey, et al, 1994:454).

Siguiendo al mismo autor esta teoría sugiere las siguientes proposiciones:

a) La formación de un sistema no se deriva tanto de la proximidad geográfica entre el centro receptor y la "periferia" emisora como de las relaciones políticas y económicas existentes entre ambos polos.

b) Los sistemas migratorios pueden ser multipolares, es decir, pueden estar constituidos por núcleos dispersos de países receptores.

c) Consecuentemente, cada país puede formar parte de más de un sistema migratorio.

d) Debido a las versátiles condiciones políticas y económicas en las que están insertos los sistemas migratorios, su estabilidad no implica una estructura rígida.

En función de estas condiciones cambiantes, los países pueden generar nuevos sistemas, incorporarse a otros existentes o abandonar aquellos en los que se encontraban en otros momentos históricos.

La propuesta de Kritz y Zlotnik (1992:3) para caracterizar a los sistemas migratorios sostiene que tanto las migraciones humanas, como otros tipos de vínculos (históricos, culturales, coloniales y tecnológicos), relacionan países, constituyendo un sistema. Los procesos migratorios ocurren en contextos nacionales en los cuales las dimensiones sociales, económicas, políticas y tecnológicas están constantemente cambiando, en parte gracias a su propia contribución. Según los autores, las personas se desplazan en ambas direcciones, posiblemente en múltiples etapas, así como también el número de países que integran el sistema probablemente crezca en poco tiempo. Además, la población que circula en él no solo está compuesta por migrantes permanentes, sino también estudiantes y turistas con residencia eventual. Generalmente, los países receptores se caracterizan por altos salarios y mejores condiciones de vida, mientras que los emisores lo hacen por sus bajos salarios y peores condiciones de bienestar social. 


\section{La migración desde Latinoamérica y el Caribe a Europa}

Aunque la información disponible es incompleta y no permite identificar con exactitud qué países latinoamericanos y caribeños y de la OCDE (excepto Estados Unidos) podrían integrar los sistemas migratorios ${ }^{5}$, se pueden señalar algunas evidencias. España, en concreto, ya era en el año 2000 el país de la OCDE que tenía la mayor proporción de latinoamericanos entre su población inmigrante. Además, ha sido en la última década el segundo receptor de población latinoamericana después de Estados Unidos y el primero en Europa (entre 1998 y 2008 las personas de origen latinoamericano registradas en España pasaron de 290.446 a 2.298.787) ${ }^{6}$. Italia (223.994), Países Bajos (221.593), Reino Unido (84.236), Francia (79.932) y Portugal (74.940), en ese orden, eran hacia el año 2000 los países con mayor población de origen latinoamericano y caribeño en Europa después de España. Lamentablemente, la información estadística disponible no permite realizar series temporales completas de la evolución de los stocks de latinoamericanos y caribeños en los años sucesivos en estos países, pero si permite observar a grandes rasgos una tendencia creciente, por lo menos hasta 2007. Sabemos, además, que la mayor parte de los flujos continuaron siendo laborales y contenían una proporción significativa de mujeres, lo cual eran una seña de identidad ${ }^{7}$.

En Italia la inmigración se compone fundamentalmente de sudamericanos (sobre todo argentinos, brasileños, venezolanos y peruanos, en ese orden), todos ellos (excepto peruanos) con importantes diásporas de italianos constituidas durante la migración masiva de finales del siglo XIX y el primer tercio del XX. En los casos de Países Bajos, Reino Unido, Francia y Portugal los contingentes más numerosos proceden de antiguas colonias en Sudamérica (Brasil y Surinam) y el Caribe (Jamaica, Trinidad y Tobago, Dominica; etc.) en las cuales también existen importantes diásporas y lazos familiares, culturales y económicos significativos. Esta migración también se caracteriza porque guarda relación con una modalidad de retorno diferido generacionalmente, ya que algunas personas recuperaron la ciudadanía de origen de sus antepasados inmigrantes (Martínez Pizarro, 2008:154).

En suma, la mayor parte de las migraciones extra regionales en Latinoamérica y el Caribe se dirigen hacia países de la OCDE; antiguos "centros metropolitanos" donde partieron antaño conquistadores, colonizadores y emigrantes económicos. Por tanto, estos desplazamientos se producen en el marco general de relaciones postcoloniales de orden económico, cultural y político. Sin embargo, existen otros flujos como ecuatorianos y peruanos hacia Italia, colombianos hacia Reino Unido, etc., que deben inscribirse en el marco de dos dinámicas complementarias: por un lado, la de la globalización de la migración internacional; y por otro, la de contextos coyunturales en los países de salida y de destino. Contextos de orden social (diferencias de bienestar);

\footnotetext{
${ }^{5}$ Acerca de los problamas de comparabilidad de las estadísticas sobre migración internacional ver OECD, 2008 Op. Cit.

6 Según el Padrón de Habitantes (INE), las últimas cifras a $1^{\circ}$ de enero de 2010, aún provisionales, indican que el stock ascendió a 2.392 .644 personas.

${ }^{7}$ International Migration Database, OECD, 2010 Disponible en internet [http://stats.oecd.org] Acceso el 04/05/2010
} 
económico (desempleo versus demanda de trabajadores; diferencias salariales) demográfico (exceso de mano de obra joven por abandono temprano del sistema educativo versus escasez de nuevos cohortes que deberían ingresar al mercado de trabajo) y político (desencanto con las promesas de la "nueva" democracia versus confianza en regímenes estables promotores de desarrollo social).

\section{¿Es posible identificar un sistema migratorio iberoamericano? Análisis de la evidencia empírica}

Haciendo un poco de historia hallamos que el volumen de latinoamericanos en España comenzó a adquirir relevancia en las décadas de 1960 y 1970. Como señala Actis (2009), en torno a 1960 la colonia más numerosa era la cubana, conformada por exiliados políticos, y en 1965 crecieron los venezolanos, que configuraron el segundo núcleo nacional tras los cubanos. Al finalizar los años sesenta también se habían duplicado los argentinos, colombianos, chilenos y peruanos, como producto de fin de la autarquía española. En los '70 creció el número de los procedentes de Uruguay, Chile y Argentina como consecuencia de los exilios generados por las respectivas dictaduras militares. En la década siguiente aumentó el número de dominicanos y peruanos, convirtiéndose en los principales colectivos de la inmigración latinoamericana.

Pero mayor parte de la inmigración latinoamericana siguió la evolución del conjunto de inmigración extranjera a España. Según la Encuesta Nacional de Inmigrantes (INE, 2007), el $79,9 \%$ de la población de origen latinoamericano que residía en el país en 2007 llegó durante la última década (el 35,4\% llegó entre 1997 y 2001 y el 44,5\% entre 2002 y 2007), una proporción superior a la que presenta el conjunto de la inmigración extranjera que asciende al $70,1 \%$ (28,9\% entre 1997 y 2001 y $41,2 \%$ entre 2002 y 2007$)$.

En la Tabla I presentamos la evolución anual de este extraordinario proceso inmigratorio, en términos absolutos y relativos, discriminando la población latinoamericana de acuerdo a las sub regiones de origen. En la primera fila puede observarse que el stock de personas creció en más de dos millones entre 1998 y 2008 (de 290.446 a 2.298.787), lo cual equivale a un 691\%. Sin embargo, este crecimiento no fue paulatino sino que se concentró entre 2000 y 2003, moderándose después para volver a crecer en 2008. Con todo, la velocidad y magnitud de esta migración ubicó a los latinoamericanos como "primera minoría" de población de origen extranjero en España $(37,4 \%)$ relegando a los procedentes de países de la EU-27 (36,2\%) y de África $(15,8 \%)$. De ahí que haya autores que califiquen este período como de "latinoamericanización de la inmigración extranjera en España" (Domingo, 2005)

Esta enorme expansión se debió principalmente a la llegada de población procedente de Sudamérica (88\%), y en mucho menor medida a personas de origen centroamericano (10\%) y mexicano (2\%). Nótese que el conjunto de personas de origen sudamericano era de 213.591 en 1998 mientras diez años 
después ascendía a 1.992.625 personas. Esto supone un incremento de 832\%. En cambio, los centroamericanos, que ya partían de un stock tres veces inferior (63.068 personas), sólo aumentaron en el mismo período 318\%, alcanzando en 2008 los 263.749 efectivos. En el caso de personas procedentes de México, constituían un volumen muy inferior a los dos grupos anteriores en 1998 (13.787 personas) y su incremento absoluto y relativo en los diez años siguientes (28.626 personas, un 207\%), si bien acompañó la tendencia creciente del conjunto, no modificó la distribución regional.

Tabla I. España. Stock, crecimiento anual y acumulado de población de origen latinoamericano y caribeño según región de origen (1998-2008). A $1^{\circ}$ de enero. En valores absolutos y porcentajes horizontales.

\begin{tabular}{|c|c|c|c|c|c|c|}
\hline & 1998 & & & 104 & 2006 & 008 \\
\hline $\begin{array}{l}\text { AMÉRICA LATINA } \\
\text { Crecimiento anual } \\
\text { Crecimiento } \\
\text { acumulado }\end{array}$ & 290446 & $\begin{array}{r}390035 \\
22,60 \% \\
34,30 \% \\
\end{array}$ & $\begin{array}{l}977707 \\
51,30 \% \\
236,60 \%\end{array}$ & $\begin{array}{l}1557131 \\
16,90 \% \\
436,10 \%\end{array}$ & $\begin{array}{c}1902000 \\
6,00 \% \\
554,90 \%\end{array}$ & $\begin{array}{r}2298787 \\
13,30 \% \\
691,50 \%\end{array}$ \\
\hline $\begin{array}{l}\text { AMERICA CENTRAL } \\
\text { Y CARIBE } \\
\text { Crecimiento anual } \\
\text { Crecimiento } \\
\text { acumulado }\end{array}$ & 63068 & $\begin{array}{r}85154 \\
21,50 \% \\
35,00 \% \\
\end{array}$ & $\begin{array}{r}125163 \\
19,40 \% \\
98,50 \% \\
\end{array}$ & $\begin{array}{r}158559 \\
8,50 \% \\
151,40 \% \\
\end{array}$ & $\begin{array}{c}199028 \\
8,80 \% \\
215,60 \% \\
\end{array}$ & $\begin{array}{r}263749 \\
19,30 \% \\
318,20 \% \\
\end{array}$ \\
\hline $\begin{array}{c}\text { México } \\
\text { Crecimiento anual } \\
\text { Crecimiento } \\
\text { acumulado }\end{array}$ & 13787 & $\begin{array}{r}16602 \\
14,20 \% \\
20,40 \% \\
\end{array}$ & $\begin{array}{r}22476 \\
18,90 \% \\
63,00 \% \\
\end{array}$ & $\begin{array}{r}32304 \\
12,30 \% \\
134,30 \% \\
\end{array}$ & $\begin{array}{c}40574 \\
6,40 \% \\
194,30 \% \\
\end{array}$ & $\begin{array}{r}42413 \\
8,40 \% \\
207,60 \% \\
\end{array}$ \\
\hline $\begin{array}{l}\text { AMERICA DEL SUR } \\
\text { Crecimiento anual } \\
\text { Crecimiento } \\
\text { acumulado }\end{array}$ & 213591 & $\begin{array}{r}288279 \\
23,50 \% \\
35,00 \%\end{array}$ & $\begin{array}{l}830068 \\
58,90 \% \\
288,60 \%\end{array}$ & $\begin{array}{l}1366268 \\
18,10 \% \\
539,70 \%\end{array}$ & $\begin{array}{c}1662398 \\
5,70 \% \\
678,30 \%\end{array}$ & $\begin{array}{r}1992625 \\
12,60 \% \\
832,90 \%\end{array}$ \\
\hline
\end{tabular}

Fuente: Padrón de Habitantes (INE) y elaboración propia

Como puede observarse en la tabla, los incrementos más significativos del stock de latinoamericanos se produjeron en 2000, 2001, 2002 y 2003 con tasas de $22 \%, 65 \%, 51 \%$ y $36 \%$, respectivamente. La población procedente de Sudamérica fue la protagonista principal en este escenario ya que creció en proporciones muy superiores a la centroamericana y caribeña, sobre todo a partir de $2001(23,5 \%, 81,2 \%, 58,9 \%$ y $39,4 \%$ frente a $21,5 \%, 23,1 \%, 19,4 \%$ y $16,8 \%$ respectivamente). Luego, entre 2004 y 2007, el crecimiento del stock fue moderándose $(16,9 \%, 15,2 \%, 6,0 \%$ y 6,7\%), pero en 2008 vuelve a crecer el doble que el año anterior $(13,3 \%)$ revistiendo, a priori, la tendencia menguante. 
Sin embargo, en 2006 se produjo un cambio en la composición regional del crecimiento de latinoamericanos que merece subrayarse. Ese año, por primera vez, el stock de centroamericanos y caribeños comenzó a crecer a un ritmo moderadamente superior al de la población sudamericana $(8,8 \%, 11,1 \%$ y $19,3 \%$ frente a $5,7 \%, 6,4 \%$ y $12,6 \%$ respectivamente). Y si bien aún no pueden extraerse conclusiones al respecto, queda en evidencia un cambio que merecerá atención en futuras investigaciones.

Ahora focalizaremos el crecimiento absoluto y relativo de la inmigración latinoamericana durante la última década, distinguiendo la sub-región y el país de origen. Comenzamos con la Tabla II, observando la población procedente de Centroamérica y el Caribe. El primer hecho a destacar es que todos los países con presencia significativa en España han incrementado su stock. El segundo, que existen notables diferencias entre ellos en el volumen inicial de población en 1998 y en el ritmo de crecimiento anual y acumulado durante los diez años siguientes.

La constitución del stock de la inmigración dominicana se inició a finales de los años ochenta y creció significativamente durante los noventa. Si bien su volumen no es numéricamente muy significativo frente a las magnitudes de la diáspora dominicana en Estados Unidos, presenta rasgos característicos que le confieren un carácter distintivo como son su altísimo grado de feminización (75\% según los registros del Padrón de Habitantes a $1^{\circ}$ de enero de 1996) y su origen rural ${ }^{8}$.

Por su parte, los cubanos son uno de los grupos de inmigrantes más antiguos en España. A partir de la Revolución Cubana de 1959, comenzó a llegar una diáspora política que se diferenciaba de otras colonias debido alto número de solicitantes de asilo y de nacionalizaciones ${ }^{9}$. Pero a mediados de la década de 1990 y hasta 2003 aproximadamente, comenzó a incrementarse la llegada de nuevos flujos y sobre todo a transformarse su composición con más presencia de migrantes meramente económicos (Ver González Yanci y Aguilera Arilla, 2002).

No obstante, el crecimiento del stock de dominicanos y cubanos no explica todo el crecimiento de centroamericanos y caribeños durante la década, ni la diferencia positiva entre éste y el de la población sudamericana entre 2006 y 2008. La explicación se encuentra en el aumento espectacular del stock de nicaragüenses y hondureños, y en menor medida de salvadoreños $y$ guatemaltecos.

\footnotetext{
${ }^{8}$ La migración dominicana estuvo protagonizada en sus inicios por mujeres procedentes de áreas rurales del país que migraban solas y en una alta proporción como proveedoras principales de sus hogares. Este patrón es diferente a la migración dominicana a Estados Unidos (destino principal de la migración dominicana), protagonizada en mayor medida por hombres procedentes de las clases medias urbanas (Romero Valiente 2003).

${ }^{9}$ Tanto fue así que según el Censo de 1970 eran el colectivo latinoamericano más numeroso en España con 18.492 efectivos, lo cual representaba el 83\% del conjunto de centroamericanos y caribeños y el $36 \%$ del total de latinoamericanos en España.
} 
En efecto, el stock de personas procedentes de Nicaragua pasó de 1.432 a 10.098 efectivos, lo que representa un aumento de 605,2\%; el de Honduras de 1.672 a 23.673 , un aumento de $1.315,8 \%$. Y aunque el crecimiento del conjunto de personas oriundas de El Salvador y Guatemala no haya alcanzado estas proporciones, de todos modos fue significativo ya que acompañó el crecimiento de toda la región, alrededor de 320\% (Tabla II). Sin duda, la escasa perspectiva temporal no permite plantear más que hipótesis sobre este proceso, las que abordaremos luego en las conclusiones de este trabajo.

Tabla II. España. España. Stock, crecimiento anual y acumulado de población de origen centroamericano y caribeño según país de procedencia (1998-2008). A $1^{\circ}$ de enero. En valores absolutos y porcentajes horizontales.

\begin{tabular}{|c|c|c|c|c|c|c|}
\hline & 1998 & 2000 & 2002 & 2004 & 2006 & 2008 \\
\hline $\begin{array}{c}\text { AMERICA } \\
\text { CENTRAL } \\
\text { Y CARIBE } \\
\text { Crecimiento } \\
\text { anual } \\
\text { Crecimiento } \\
\text { acumulado } \\
\end{array}$ & 63068 & $\begin{array}{r}85154 \\
21,50 \% \\
35,00 \% \\
\end{array}$ & $\begin{array}{l}125163 \\
19,40 \% \\
98,50 \% \\
\end{array}$ & $\begin{array}{c}158559 \\
8,50 \% \\
151,40 \% \\
\end{array}$ & $\begin{array}{c}199028 \\
8,80 \% \\
215,60 \% \\
\end{array}$ & $\begin{array}{r}263749 \\
19,30 \% \\
318,20 \% \\
\end{array}$ \\
\hline $\begin{array}{c}\text { Costa Rica } \\
\text { Crecimiento anual } \\
(\%) \\
\text { Crecimiento } \\
\text { acumulado (\%) } \\
\end{array}$ & 921 & $\begin{array}{c}1110 \\
15,60 \% \\
20,50 \% \\
\end{array}$ & $\begin{array}{c}1501 \\
17,40 \% \\
63,00 \% \\
\end{array}$ & $\begin{array}{r}1946 \\
5,50 \% \\
111,30 \% \\
\end{array}$ & $\begin{array}{c}2373 \\
5,30 \% \\
157,70 \% \\
\end{array}$ & $\begin{array}{c}2883 \\
16,50 \% \\
213,00 \% \\
\end{array}$ \\
\hline $\begin{array}{c}\text { Cuba } \\
\text { Crecimiento anual } \\
(\%) \\
\text { Crecimiento } \\
\text { acumulado (\%) } \\
\end{array}$ & 31223 & $\begin{array}{r}40637 \\
19,30 \% \\
30,20 \% \\
\end{array}$ & $\begin{array}{r}57669 \\
17,50 \% \\
84,70 \% \\
\end{array}$ & $\begin{array}{r}69048 \\
5,00 \% \\
121,10 \% \\
\end{array}$ & $\begin{array}{r}79228 \\
3,50 \% \\
153,70 \% \\
\end{array}$ & $\begin{array}{r}92583 \\
11,40 \% \\
196,50 \% \\
\end{array}$ \\
\hline $\begin{array}{c}\text { Dominica } \\
\text { Crecimiento anual } \\
(\%) \\
\text { Crecimiento } \\
\text { acumulado (\%) } \\
\end{array}$ & 514 & $\begin{array}{c}564 \\
13,00 \% \\
9,70 \% \\
\end{array}$ & $\begin{array}{c}732 \\
11,20 \% \\
42,40 \% \\
\end{array}$ & $\begin{array}{c}766 \\
5,90 \% \\
49,00 \% \\
\end{array}$ & $\begin{array}{c}797 \\
0,00 \% \\
55,10 \% \\
\end{array}$ & $\begin{array}{c}802 \\
4,80 \% \\
56,00 \% \\
\end{array}$ \\
\hline $\begin{array}{c}\text { El Salvador } \\
\text { Crecimiento anual } \\
(\%) \\
\text { Crecimiento } \\
\text { acumulado (\%) } \\
\end{array}$ & 1708 & $\begin{array}{c}2050 \\
13,80 \% \\
20,00 \% \\
\end{array}$ & $\begin{array}{c}3041 \\
24,60 \% \\
78,00 \% \\
\end{array}$ & $\begin{array}{r}4043 \\
9,20 \% \\
136,70 \% \\
\end{array}$ & $\begin{array}{r}5102 \\
9,70 \% \\
198,70 \% \\
\end{array}$ & $\begin{array}{c}7120 \\
24,40 \% \\
316,90 \% \\
\end{array}$ \\
\hline $\begin{array}{c}\text { Guatemala } \\
\text { Crecimiento anual } \\
(\%) \\
\text { Crecimiento } \\
\text { acumulado (\%) } \\
\end{array}$ & 1394 & $\begin{array}{c}1757 \\
20,80 \% \\
26,00 \% \\
\end{array}$ & $\begin{array}{c}2523 \\
20,10 \% \\
81,00 \% \\
\end{array}$ & $\begin{array}{c}3343 \\
8,30 \% \\
139,80 \% \\
\end{array}$ & $\begin{array}{c}4321 \\
10,90 \% \\
210,00 \% \\
\end{array}$ & $\begin{array}{c}5861 \\
21,30 \% \\
320,40 \% \\
\end{array}$ \\
\hline $\begin{array}{c}\text { Honduras } \\
\text { Crecimiento anual } \\
(\%) \\
\text { Crecimiento } \\
\text { acumulado (\%) } \\
\end{array}$ & 1672 & $\begin{array}{c}2235 \\
22,50 \% \\
33,70 \% \\
\end{array}$ & $\begin{array}{c}3948 \\
31,00 \% \\
136,10 \% \\
\end{array}$ & $\begin{array}{c}6361 \\
21,30 \% \\
280,40 \% \\
\end{array}$ & $\begin{array}{r}10652 \\
28,00 \% \\
537,10 \% \\
\end{array}$ & $\begin{array}{r}23673 \\
48,90 \% \\
1315,80 \% \\
\end{array}$ \\
\hline $\begin{array}{c}\text { Nicaragua } \\
\text { Crecimiento anual }\end{array}$ & 1432 & $\begin{array}{c}1789 \\
18,80 \%\end{array}$ & $\begin{array}{c}2298 \\
13,10 \%\end{array}$ & $\begin{array}{c}2833 \\
7,90 \%\end{array}$ & $\begin{array}{c}4204 \\
24,80 \%\end{array}$ & $\begin{array}{c}10098 \\
64,70 \%\end{array}$ \\
\hline
\end{tabular}




\begin{tabular}{|c|c|c|c|c|c|c|}
$\begin{array}{c}(\%) \\
\text { Crecimiento } \\
\text { acumulado (\%) }\end{array}$ & & $24,90 \%$ & $60,50 \%$ & $97,80 \%$ & $193,60 \%$ & $605,20 \%$ \\
\hline \hline $\begin{array}{c}\text { Panamá } \\
\text { Crecimiento anual } \\
\text { (\%) } \\
\text { Crecimiento } \\
\text { acumulado (\%) }\end{array}$ & 1767 & 1942 & 2381 & 2980 & 3520 & 4241 \\
\hline \hline $\begin{array}{c}\text { República } \\
\text { Dominicana } \\
\text { Crecimiento anual } \\
\text { (\%) }\end{array}$ & 21660 & 32206 & 49918 & 65777 & 87111 & 114707 \\
$\begin{array}{c}\text { Crecimiento } \\
\text { acumulado (\%) }\end{array}$ & & $26,60 \%$ & $21,50 \%$ & $11,30 \%$ & $11,60 \%$ & $18,70 \%$ \\
\hline $\begin{array}{c}\text { Resto de América } \\
\text { Central }\end{array}$ & $777,20 \%$ & $6,80 \%$ & $6,00 \%$ & $11,90 \%$ \\
$\begin{array}{c}\text { y Caribe } \\
\text { Crecimiento anual } \\
\text { (\%) }\end{array}$ & $78,70 \%$ & $130,50 \%$ & $203,70 \%$ & $302,20 \%$ & $429,60 \%$ \\
\hline $\begin{array}{c}\text { Crecimiento } \\
\text { acumulado (\%) }\end{array}$ & & $10,60 \%$ & $16,60 \%$ & $9,00 \%$ & $0,40 \%$ & $5,30 \%$ \\
\hline
\end{tabular}

Fuente: Padrón de Habitantes (INE) y elaboración propia

Para analizar la migración de sudamericanos hacia España en la última década, presentamos en la Tabla III la evolución de esta población en términos absolutos y relativos. Como se puede apreciar en ella, en 1998 la presencia de sudamericanos giraba alrededor de dos grupos nacionales que acaparaban la mitad del conjunto: argentinos (61.323 personas) y venezolanos (46.388 personas).

Se trata de un stock antiguo, y al igual que el cubano, conformado por flujos diversos (económicos, políticos, familiares, retornos, etc.) que se originaron a partir de los vínculos establecidos con España después de la emigración masiva de españoles ${ }^{10}$. Ya el Censo de 1970 registraba 9.436 venezolanos y 7.784 argentinos, siendo los colectivos más importantes de población sudamericana (33\% y $27 \%$ respectivamente), y también constituyendo una proporción significativa del conjunto de latinoamericanos (18\% y $15 \%$ respectivamente).

Continuando con el análisis de la tabla, observamos que a gran distancia de los argentinos y venezolanos le siguen en volumen los peruanos (26.900). Como sostiene Merino Hernando, si bien esta inmigración comenzó realmente en la década de los años sesenta, desde entonces y hasta mediados de los ochenta

\footnotetext{
${ }^{10}$ La migración de españoles a Venezuela se produjo sobre todo en la postguerra civil y procedía mayoritariamente de las Islas Canarias. Se estima que más de 300.000 canarios llegaron a vivir en la "octava isla", como llegaron a denominar a este destino americano (Delgado y Lozano, 2007). En cambio, la emigración española a Argentina fue un proceso más complejo y de mayores dimensiones ya que implicó a más de dos millones de personas, adoptó diferentes formas y volúmenes durante un siglo aproximadamente (mediados del siglo XIX a mediados del Siglo XX) y estuvo compuesto por migrantes de toda la península aunque predominaron los de origen gallego, catalán, asturiano y andaluz (Véase Sánchez Alonso, 1992).
} 
su presencia era poco destacable. En realidad, su volumen creció vertiginosamente entre 1990 y 1994, singularizándose 1991 por el número de entradas.

Por último, en 1998 también destaca una incipiente inmigración colombiana (17.928) y dos grupos que contaban hasta ese momento con una presencia mayoritaria de ex exiliados políticos que llegaron en los setentas: chilenos (16.984) y uruguayos (15.577). Además, en el caso concreto de los uruguayos, contenía fuertes vínculos con la emigración previa de españoles hacia este país (Morales Mena, 2008).

Si observamos ahora cuáles son los países de origen de la mayor parte de la inmigración procedente de Sudamérica en el año 2008, observamos que estos han cambiado. Los colectivos que más han crecido y poseen los stocks más significativos son los procedentes de Ecuador, Colombia, Argentina. Y hacia el final de la década observamos que han crecido notablemente los inmigrantes procedentes de Paraguay y Bolivia.

En primer lugar, en el transcurso de diez años el volumen de población de origen ecuatoriano aumentó en 453.102 personas (8493\%), produciéndose los mayores flujos entre 2001 y 2003. De esta forma se convirtió en el primer grupo de inmigrantes procedente de Latinoamérica (representan el $20 \%$ del total) y el tercero más importante del país, después de rumanos y marroquíes ${ }^{11}$. En 2006 y 2007 el crecimiento del stock fue negativo, declinación que podría atribuirse a un "efecto boomerang" de retornos inmediatos usual en las migraciones masivas, y en 2008 ha vuelto a crecer moderadamente. Por tanto, siguiendo a Gómez Ciriano (2007), es probable que el ciclo de emigración económica de ecuatorianos hacia España, al menos tal como ha venido sucediendo en las últimas décadas, se encuentra su la etapa final.

Tabla III. España. Stock, crecimiento anual y acumulado de población de origen sudamericano según país de procedencia (1998-2008). A $31^{\circ}$ de enero. En valores absolutos y porcentajes horizontales.

\begin{tabular}{|l|r|r|r|r|r|r|}
\hline & $\mathbf{1 9 9 8}$ & $\mathbf{2 0 0 0}$ & $\mathbf{2 0 0 2}$ & $\mathbf{2 0 0 4}$ & $\mathbf{2 0 0 6}$ & $\mathbf{2 0 0 8}$ \\
\hline $\begin{array}{l}\text { AMERICA DEL } \\
\text { SUR }\end{array}$ & 213591 & 288279 & 830068 & 1366268 & 1662398 & 1992625 \\
$\begin{array}{l}\text { Crecimiento } \\
\text { anual (\%) } \\
\text { Crecimiento } \\
\text { acumulado }\end{array}$ & & $23,50 \%$ & $58,90 \%$ & $18,10 \%$ & $5,70 \%$ & $12,60 \%$ \\
\hline $\begin{array}{l}\text { Argentina } \\
\text { Crecimiento }\end{array}$ & 61323 & 70491 & 118903 & 226548 & 271444 & 290281 \\
$\begin{array}{l}\text { anual (\%) } \\
\text { Crecimiento }\end{array}$ & & $10,10 \%$ & $40,10 \%$ & $18,20 \%$ & $4,20 \%$ & $6,30 \%$ \\
acumulado & & $15,00 \%$ & $93,90 \%$ & $269,40 \%$ & $342,60 \%$ & $373,40 \%$ \\
\hline \hline $\begin{array}{l}\text { Bolivia } \\
\text { Crecimiento }\end{array}$ & 2581 & 3723 & 15520 & 54442 & 140740 & 240912 \\
\hline
\end{tabular}

${ }^{11}$ De acuerdo al Padrón de Habitantes, a $1^{\circ}$ de enero de 2008 había en España 706.164 personas de origen rumano, 683.102 de origen marroquí y 458.437 de origen ecuatoriano; las cuales representan el $11,7 \%, 11,3 \%$ y $7,6 \%$ de nacidos en el extranjero. 


\begin{tabular}{|c|c|c|c|c|c|c|}
\hline $\begin{array}{l}\text { anual }(\%) \\
\text { Crecimiento } \\
\text { acumulado }\end{array}$ & & $44,20 \%$ & $501,30 \%$ & $2009,30 \%$ & $5352,90 \%$ & $9234,10 \%$ \\
\hline $\begin{array}{l}\text { Brasil } \\
\text { Crecimiento } \\
\text { anual }(\%) \\
\text { Crecimiento } \\
\text { acumulado }\end{array}$ & 19180 & $\begin{array}{r}25037 \\
19,60 \% \\
30,50 \% \\
\end{array}$ & $\begin{array}{r}39474 \\
23,60 \% \\
105,80 \% \\
\end{array}$ & $\begin{array}{r}55014 \\
14,70 \% \\
186,80 \% \\
\end{array}$ & $\begin{array}{r}93396 \\
27,80 \% \\
386,90 \% \\
\end{array}$ & $\begin{array}{r}142149 \\
25,30 \% \\
641,10 \% \\
\end{array}$ \\
\hline $\begin{array}{l}\text { Chile } \\
\text { Crecimiento } \\
\text { anual (\%) } \\
\text { Crecimiento } \\
\text { acumulado }\end{array}$ & 16984 & \begin{tabular}{|r|}
20086 \\
$12,30 \%$ \\
$18,30 \%$ \\
\end{tabular} & $\begin{array}{r}30768 \\
25,10 \% \\
81,20 \% \\
\end{array}$ & $\begin{array}{r}44167 \\
13,30 \% \\
160,10 \% \\
\end{array}$ & $\begin{array}{r}57864 \\
10,00 \% \\
240,70 \% \\
\end{array}$ & $\begin{array}{r}66874 \\
11,10 \% \\
293,70 \% \\
\end{array}$ \\
\hline $\begin{array}{l}\text { Colombia } \\
\text { Crecimiento } \\
\text { anual (\%) } \\
\text { Crecimiento } \\
\text { acumulado }\end{array}$ & 17928 & $\begin{array}{r}35668 \\
65,00 \% \\
99,00 \% \\
\end{array}$ & $\begin{array}{r}205308 \\
105,40 \% \\
1045,20 \% \\
\end{array}$ & \begin{tabular}{|r|}
264503 \\
$2,00 \%$ \\
$1375,40 \%$ \\
\end{tabular} & $\begin{array}{r}286969 \\
-0,40 \% \\
1500,70 \% \\
\end{array}$ & $\begin{array}{r}330419 \\
13,30 \% \\
1743,00 \% \\
\end{array}$ \\
\hline $\begin{array}{l}\text { Ecuador } \\
\text { Crecimiento } \\
\text { anual (\%) } \\
\text { Crecimiento } \\
\text { acumulado }\end{array}$ & 5335 & $\begin{array}{r}21734 \\
160,20 \% \\
307,40 \% \\
\end{array}$ & $\begin{array}{r}259779 \\
84,70 \% \\
4769,30 \% \\
\end{array}$ & $\begin{array}{r}470090 \\
21,30 \% \\
8711,40 \% \\
\end{array}$ & $\begin{array}{r}456641 \\
-6,30 \% \\
8459,30 \% \\
\end{array}$ & $\begin{array}{r}458437 \\
5,50 \% \\
8493,00 \% \\
\end{array}$ \\
\hline $\begin{array}{l}\text { Paraguay } \\
\text { Crecimiento } \\
\text { anual (\%) } \\
\text { Crecimiento } \\
\text { acumulado }\end{array}$ & 1296 & $\begin{array}{r}1550 \\
13,60 \% \\
19,60 \% \\
\end{array}$ & $\begin{array}{r}2370 \\
27,20 \% \\
82,90 \% \\
\end{array}$ & $\begin{array}{r}7020 \\
91,30 \% \\
441,70 \% \\
\end{array}$ & $\begin{array}{r}30155 \\
70,20 \% \\
2226,80 \% \\
\end{array}$ & $\begin{array}{r}68885 \\
43,90 \% \\
5215,20 \% \\
\end{array}$ \\
\hline $\begin{array}{l}\text { Perú } \\
\text { Crecimiento } \\
\text { anual }(\%) \\
\text { Crecimiento } \\
\text { acumulado }\end{array}$ & 26900 & $\begin{array}{r}37453 \\
22,60 \% \\
39,20 \% \\
\end{array}$ & $\begin{array}{r}59035 \\
24,80 \% \\
119,50 \% \\
\end{array}$ & $\begin{array}{r}88754 \\
21,80 \% \\
229,90 \% \\
\end{array}$ & $\begin{array}{r}123464 \\
14,30 \% \\
359,00 \% \\
\end{array}$ & $\begin{array}{r}162425 \\
18,60 \% \\
503,80 \% \\
\end{array}$ \\
\hline $\begin{array}{l}\text { Uruguay } \\
\text { Crecimiento } \\
\text { anual (\%) } \\
\text { Crecimiento } \\
\text { acumulado }\end{array}$ & 15577 & \begin{tabular}{|c|}
17699 \\
$9,40 \%$ \\
$13,60 \%$ \\
\end{tabular} & $\begin{array}{r}27161 \\
33,10 \% \\
74,40 \% \\
\end{array}$ & $\begin{array}{r}55307 \\
36,50 \% \\
255,10 \% \\
\end{array}$ & $\begin{array}{r}76635 \\
9,00 \% \\
392,00 \% \\
\end{array}$ & $\begin{array}{r}87345 \\
9,40 \% \\
460,70 \% \\
\end{array}$ \\
\hline $\begin{array}{l}\text { Venezuela } \\
\text { Crecimiento } \\
\text { anual (\%) } \\
\text { Crecimiento } \\
\text { acumulado }\end{array}$ & 46388 & $\begin{array}{r}54719 \\
10,50 \% \\
18,00 \% \\
\end{array}$ & $\begin{array}{r}71597 \\
14,90 \% \\
54,30 \% \\
\end{array}$ & $\begin{array}{r}100258 \\
20,00 \% \\
116,10 \% \\
\end{array}$ & $\begin{array}{r}124851 \\
7,50 \% \\
169,10 \% \\
\end{array}$ & $\begin{array}{r}144593 \\
10,70 \% \\
211,70 \% \\
\end{array}$ \\
\hline $\begin{array}{l}\text { Resto de } \\
\text { América } \\
\text { del Sur } \\
\text { Crecimiento } \\
\text { anual } \\
\text { Crecimiento } \\
\text { acumulado }\end{array}$ & 99 & $\begin{array}{l}11,30 \% \\
19,20 \%\end{array}$ & $\begin{array}{l}10,90 \% \\
53,50 \% \\
\end{array}$ & $\begin{array}{l}-5,20 \% \\
66,70 \%\end{array}$ & $\begin{array}{l}15,50 \% \\
141,40 \%\end{array}$ & $208,10 \%$ \\
\hline
\end{tabular}

Fuente: Padrón de Habitantes (INE) y elaboración propia

En segundo término, aunque históricamente Colombia se había caracterizado por una moderada movilidad internacional de su población, el colectivo colombiano en España experimentó un aumento espectacular durante este 
(1.743\%), sobre todo entre 2000 y 2002 (65\%, 180,2\% y $105,4 \%$ respectivamente). A partir de 2004 y hasta 2007 el aumento del stock se ralentiza bruscamente, incluso llega a decrecer en 2006 por el mismo efecto "boomerang" descrito antes, pero en 2008 vuelve a crecer $(13,3 \%)$, lo cual podría indicar que el ciclo migratorio está ingresando ya en una fase de estabilización. Este proceso migratorio derivó en un stock de 330.419 personas que supone el 14,4\% del conjunto de latinoamericanos en 2008.

El tercer colectivo de latinoamericanos con mayor cantidad de inmigrantes en España a $1^{0}$ de enero de 2008 era el de argentinos. Sumaban 290.281 personas, lo cual supone un incremento acumulado de $373,4 \%$ desde 1998 . Si bien se trata de un grupo antiguo en el país como ya hemos visto, en la última década, sobre todo entre 2001 y 2003, se renovó con la llegada de nuevos inmigrantes.

Finalmente restaría mencionar dos colectivos que han crecido significativamente su stock en los últimos años de la última década: bolivianos y paraguayos. En el caso del colectivo boliviano, fue el que más ha crecido desde 1998 (9.234,1\%). En ese año se encontraban empadronados 2.581 personas y diez años después sumaban 240.912. Los incrementos más significativos se registraron en el quinquenio $2001-2005$, y si bien en los años posteriores el aumento se ha ido reduciendo progresivamente, aún en 2008 ascendía al 20\%. Probablemente, la exigencia de visado para ingresar a la Unión europea impuesta a partir de abril de 2007 reducirá los flujos de entrada estabilizando esta migración.

En el caso de la inmigración procedente de Paraguay, se trata de flujos recientes que comenzaron a crecer vertiginosamente a partir de 2004 (91,3\%, $152,4 \%$ en 2005, 70,2\% en 2006 y 58,8\% en 2007), y que aún en 2008 su stock mostraba un incremento de 43,9\%. Esta proporción hace suponer que la migración aún está en desenvolvimiento, sobre todo teniendo en cuanta que los ciudadanos paraguayos no necesitan al día de hoy visado de entrada a la unión Europea.

\section{Composición demográfica de I a in migración latinoamericana y caribe ña en España}

Los movimientos migratorios desde América Latina y el Caribe se caracterizaron inicialmente por un predominio femenino hasta mediados de la década de 1990, una tendencia que se modificó luego hacia una equiparación entre los sexos. De todos modos, existen matices importantes de acuerdo al país de origen de los inmigrantes. Por ejemplo, la migración de argentinos registró mayor volumen de hombres durante los "picos de la inmigración" (antes de 1986, con la llegada de exiliados, y desde 2002 tras el estallido de la crisis económica); en cambio, la inmigración procedente de Ecuador y Bolivia presenta mayoría masculina hasta 1986 y predominio femenino en las décadas posteriores, a medida que se incrementaba el stock de residentes. Los casos de colombianos y peruanos son similares. 
De acuerdo a los últimos datos del Padrón de Habitantes ${ }^{12}$, el $54 \%$ de las personas nacidas en América Latina y el Caribe que residían en España, sin distinción de edad, son mujeres y el $46 \%$ hombres. No obstante, estas proporciones varían notablemente entre colectivos nacionales. Los más feminizados se pueden clasificar en dos grupos: por un lado, aquellos cuyo proceso migratorio está en pleno desenvolvimiento: Honduras, Nicaragua y Paraguay en torno al 65\%; Brasil en torno al 60\%; Panamá, Guatemala y Bolivia alrededor del 57\%; y por otro, colectivos cuyo ciclo migratorio se ha cerrado: R. Dominicana, 62\%; Colombia, Venezuela y Cuba en torno al 55\%. En cambio, otros grupos nacionales se caracterizan por un mayor equilibrio entre sexos: Ecuador, Argentina, Perú, Uruguay y Chile (Ver Tabla IV).

Según la Encuesta Nacional de Inmigrantes 2007 (ENI 2007 en adelante) la edad promedio del conjunto de la población inmigrada adulta -con 16 o más años- en España es de 38,4 años. Los inmigrantes de América del Norte $(42,3)$ y la Unión Europea $(41,8)$ se encuentran por encima de ese valor; los procedentes de Latinoamérica y el Caribe conforman el grupo más joven (36,2 años), y las demás poblaciones no comunitarias se sitúan en torno a los 37 años. Entre los latinoamericanos el perfil más envejecido corresponde a los cubanos $(48,9)$, argentinos $(40,7)$ y uruguayos $(39,2)$. En cambio, los más jóvenes son los bolivianos $(30,8)$, ecuatorianos $(32,7)$, brasileros y dominicanos (en torno a 34 años). Con edad más elevada, pero aún debajo de la media, clasificamos a colombianos y venezolanos (36), en tanto que los peruanos tienen una edad promedio que coincide con la media general de la población inmigrada $(38,4)$.

En cuanto a los cohortes etarios, la población procedente de Latinoamérica y el Caribe se concentra en los grupos de edad más jóvenes siendo su representación entre los mayores de 44 años y, sobre todo, de 65 años, relativamente reducida. En perspectiva, este mayor peso de la población joven tendió a intensificarse a comienzos de la década para posteriormente estabilizarse. Ahora si distinguimos a esta población de acuerdo a grandes grupos de edad, observamos que el $86 \%$ de los inmigrados tiene entre 16 y 64 años, o sea, que se encuentra en edad laboral. Este cohorte se encuentran especialmente los nacidos en países de reciente inmigración como El Salvador, Guatemala, Honduras (90\%), Paraguay (92\%), Nicaragua (95\%) y Brasil (89\%). Aunque también tienen elevadas proporciones Cuba (88\%) y México (90\%).

Tabla IV. España. Stock de población de origen latinoamericano y caribeño según país de procedencia y sexo (2009). A $1^{\circ}$ de enero. En porcentajes.

\begin{tabular}{|l|r|r|}
\hline & Varones & Mujeres \\
\hline América Latina & $46 \%$ & $54 \%$ \\
\hline América Central y Caribe & $40 \%$ & $60 \%$ \\
\hline Costa Rica & $47 \%$ & $53 \%$ \\
\hline Cuba & $45 \%$ & $55 \%$ \\
\hline Dominica & $34 \%$ & $66 \%$ \\
\hline
\end{tabular}

12 Datos aún provisionales a $1^{\circ}$ de enero de 2009. 


\begin{tabular}{|l|r|r|} 
El Salvador & $40 \%$ & $60 \%$ \\
\hline Guatemala & $43 \%$ & $57 \%$ \\
\hline Honduras & $32 \%$ & $68 \%$ \\
\hline Nicaragua & $31 \%$ & $69 \%$ \\
\hline Panamá & $44 \%$ & $56 \%$ \\
\hline República Dominicana & $38 \%$ & $62 \%$ \\
\hline $\begin{array}{l}\text { Resto de América Central y } \\
\text { Caribe }\end{array}$ & $50 \%$ & $50 \%$ \\
\hline México & $44 \%$ & $56 \%$ \\
\hline América del Sur & $46 \%$ & $54 \%$ \\
\hline Argentina & $52 \%$ & $48 \%$ \\
\hline Bolivia & $43 \%$ & $57 \%$ \\
\hline Brasil & $41 \%$ & $59 \%$ \\
\hline Chile & $49 \%$ & $51 \%$ \\
\hline Colombia & $44 \%$ & $56 \%$ \\
\hline Ecuador & $49 \%$ & $51 \%$ \\
\hline Paraguay & $35 \%$ & $65 \%$ \\
\hline Perú & $48 \%$ & $52 \%$ \\
\hline Uruguay & $51 \%$ & $49 \%$ \\
\hline Venezuela & $47 \%$ & $53 \%$ \\
\hline Resto de América del Sur & $43 \%$ & $57 \%$ \\
\hline
\end{tabular}

Fuente: Padrón de Habitantes (INE) y elaboración propia

Por otro lado destacan los menores de 15 años que no pueden ingresar al mercado de trabajo. Suponen el 12\% del conjunto (214.621 individuos), porcentaje que se ve superado escasamente entre los nacidos en Ecuador, Uruguay y Chile. Se trata de un indicador de la significativa presencia de familias, lo cual hace pensar en una migración con intención de asentarse a medio o largo plazo en territorio español. También, es una población que demanda prestaciones al Estado de Bienestar, sobre todo educación y sanidad.

En el extremo opuesto de la pirámide de edades nos encontramos con 34.316 personas con 65 y más años, que suponen el $2 \%$ del total de latinoamericanos, por tanto se encuentran fuera del mercado laboral y más expuestas a ser demandantes frecuentes de los servicios sanitarios. En este cohorte etario tienen mayor representación los colectivos más antiguos como son los procedentes de Cuba, Argentina y Uruguay (ver Tabla V).

Tabla V. España. Stock de población de origen latinoamericano y caribeño según país de procedencia y grupos de edad (2009). A $1^{0}$ de enero. En porcentajes

\begin{tabular}{|l|r|r|r|r|r|r|}
\hline & $\mathbf{0 - 1 4}$ & $\mathbf{1 5 - 2 4}$ & $\mathbf{2 5 - 3 4}$ & $\mathbf{3 5 - 4 4}$ & $\mathbf{4 5 - 6 4}$ & $\begin{array}{l}\mathbf{6 5} \mathbf{y} \\
\text { más }\end{array}$ \\
\hline América Latina & $12 \%$ & $17 \%$ & $33 \%$ & $22 \%$ & $15 \%$ & $2 \%$ \\
\hline América Central y Caribe & $9 \%$ & $18 \%$ & $31 \%$ & $24 \%$ & $15 \%$ & $3 \%$ \\
\hline Costa Rica & $11 \%$ & $15 \%$ & $39 \%$ & $20 \%$ & $13 \%$ & $2 \%$ \\
\hline Cuba & $6 \%$ & $12 \%$ & $25 \%$ & $29 \%$ & $22 \%$ & $6 \%$ \\
\hline
\end{tabular}




\begin{tabular}{|l|r|r|r|r|r|r|}
\hline Dominica & $12 \%$ & $20 \%$ & $24 \%$ & $26 \%$ & $15 \%$ & $3 \%$ \\
\hline El Salvador & $8 \%$ & $20 \%$ & $39 \%$ & $19 \%$ & $12 \%$ & $2 \%$ \\
\hline Guatemala & $8 \%$ & $22 \%$ & $41 \%$ & $17 \%$ & $10 \%$ & $2 \%$ \\
\hline Honduras & $9 \%$ & $20 \%$ & $40 \%$ & $20 \%$ & $10 \%$ & $1 \%$ \\
\hline Nicaragua & $5 \%$ & $16 \%$ & $42 \%$ & $25 \%$ & $12 \%$ & $1 \%$ \\
\hline Panamá & $12 \%$ & $17 \%$ & $35 \%$ & $20 \%$ & $13 \%$ & $3 \%$ \\
\hline República Dominicana & $11 \%$ & $21 \%$ & $29 \%$ & $23 \%$ & $13 \%$ & $2 \%$ \\
\hline $\begin{array}{l}\text { Resto de América Central y } \\
\text { Caribe }\end{array}$ & $13 \%$ & $6 \%$ & $22 \%$ & $17 \%$ & $26 \%$ & $15 \%$ \\
\hline México & $8 \%$ & $12 \%$ & $45 \%$ & $21 \%$ & $12 \%$ & $2 \%$ \\
\hline América del Sur & $12 \%$ & $16 \%$ & $33 \%$ & $22 \%$ & $14 \%$ & $2 \%$ \\
\hline Argentina & $12 \%$ & $12 \%$ & $32 \%$ & $20 \%$ & $19 \%$ & $4 \%$ \\
\hline Bolivia & $12 \%$ & $17 \%$ & $39 \%$ & $21 \%$ & $10 \%$ & $0 \%$ \\
\hline Brasil & $11 \%$ & $18 \%$ & $41 \%$ & $20 \%$ & $10 \%$ & $1 \%$ \\
\hline Chile & $13 \%$ & $14 \%$ & $28 \%$ & $22 \%$ & $20 \%$ & $3 \%$ \\
\hline Colombia & $12 \%$ & $18 \%$ & $29 \%$ & $24 \%$ & $16 \%$ & $2 \%$ \\
\hline Ecuador & $15 \%$ & $17 \%$ & $31 \%$ & $23 \%$ & $13 \%$ & $1 \%$ \\
\hline Paraguay & $7 \%$ & $21 \%$ & $39 \%$ & $19 \%$ & $13 \%$ & $1 \%$ \\
\hline Perú & $9 \%$ & $14 \%$ & $32 \%$ & $25 \%$ & $16 \%$ & $3 \%$ \\
\hline Uruguay & $13 \%$ & $14 \%$ & $27 \%$ & $21 \%$ & $21 \%$ & $4 \%$ \\
\hline Venezuela & $11 \%$ & $15 \%$ & $36 \%$ & $20 \%$ & $16 \%$ & $2 \%$ \\
\hline Resto de América del Sur & $4 \%$ & $3 \%$ & $18 \%$ & $27 \%$ & $35 \%$ & $14 \%$ \\
\hline
\end{tabular}

Fuente: Padrón de Habitantes (INE) y elaboración propia

La información proporcionada por la ENI 2007 acerca del nivel de estudios de esta población, indica que la mayoría (59\%) de los adultos latinoamericanos y caribeños tiene estudios secundarios; y el resto se distribuye en dos grupos: los que cuentan con educación universitaria (22\%) y los que no han superado el nivel primario (19\%). Estas proporciones ubican a este colectivo en su conjunto, por detrás de los inmigrantes procedentes de países desarrollados (América del Norte, Europa Central y del Norte), a nivel similar que los procedentes de Asia y por delante de los llegados desde África.

No obstante, estas proporciones presentan matices significativos en función del país de origen Por ejemplo, el porcentaje de universitarios entre los nacidos en Venezuela y Cuba (más del 37\%), o Argentina y Perú (31\%) superan con creces a la media. En cambio, en torno o por debajo de la media continental se sitúan los universitarios de Brasil, Uruguay y Colombia (entre 18\% y 22\%); más atrás los de Bolivia (16\%) y más aún los de Ecuador (11\%) y República Dominicana (8\%). A su vez, el $30 \%$ de los inmigrados de estos dos últimos países solo cuenta con educación primaria.

Para comprender mejor la inserción laboral de la población inmigrada desde América Latina y el Caribe, debe inscribirse en el marco de un proceso de crecimiento prolongado de la economía española, con abundante creación de empleo, drástica reducción del desempleo e incremento significativo de la 
población económicamente activa ${ }^{13}$. Esta etapa, que había comenzado en 199 finalizó con la actual crisis económica, por tanto ocupa el período en el cual arribó la mayor parte de los latinoamericanos y caribeños que residen actualmente en España.

En la tabla VI se expone la población extranjera en alta en la seguridad social discriminada según nacionalidad (de los cuales seleccionamos los grupos más significativos) y el tipo de régimen de seguridad social en que se encontraban cotizando a principios de $2009^{14}$. Los datos permiten constatar que todos los porcentajes de autónomos son muy bajos en relación con el conjunto de la población, siendo el más alto el de los argentinos (12.3\%). En el régimen de empleados del hogar, la comunidad latinoamericana ocupa los porcentajes más altos en España, destacándose los migrantes procedentes de Bolivia (33.1\%), Ecuador (13.1\%), Colombia (15.3\%), Perú (13\%) y R. Dominicana (20.9\%). Proporciones que están en sintonía con la feminización de los contingentes destacada anteriormente.

Tabla VI. España. Latinoamericanos en alta laboral en la Seguridad Social, según nacionalidad (destacando los países con mayor número de residentes) y régimen de cotización a la seguridad social, al 31 de diciembre de 2008. (Porcentajes horizontales)

\begin{tabular}{|l|r|r|r|r|}
\hline & General & Autónomo & Agrario & $\begin{array}{c}\text { E. E. } \\
\text { hogar }\end{array}$ \\
\hline Argentina & $80.9 \%$ & $12.3 \%$ & $0.7 \%$ & $6.1 \%$ \\
\hline Bolivia & $57.1 \%$ & $1.7 \%$ & $8.1 \%$ & $33.1 \%$ \\
\hline Colombia & $77.6 \%$ & $4.4 \%$ & $2.6 \%$ & $15.3 \%$ \\
\hline Cuba & s.d. & s.d. & s.d. & s.d. \\
\hline Ecuador & $72.6 \%$ & $2.7 \%$ & $11.6 \%$ & $13.1 \%$ \\
\hline Perú & $82.3 \%$ & $2.5 \%$ & $1.4 \%$ & $13.0 \%$ \\
\hline R. Dominicana & $74.6 \%$ & $3.3 \%$ & $1.1 \%$ & $20.9 \%$ \\
\hline Total extranjeros & $68.2 \%$ & $11.8 \%$ & $10.8 \%$ & $9.1 \%$ \\
\hline
\end{tabular}

Fuente: elaboración propia con datos del OPI (2009); MTI (2008)

En la medida que la simple distribución por regímenes de cotización no describe adecuadamente la situación ocupacional, en el tabla VII se muestra la distribución de los trabajadores latinoamericanos (sólo las nacionalidades con mayor presencia en el país), según diez categorías laborales del Régimen

13 Desde 1996 ha experimentado un crecimiento medio anual del 3,5\%, crecimiento que fue del $4,1 \%$ entre 1996 y 2000 y del 3,1\% entre 2001 y 2005; muy por encima del crecimiento medio del PIB de los socios de la zona euro $(2,1 \%)$, de la UE-25 (2,3\%) e incluso superior al registrado en EEUU (3,3\%). Según el informe de la Oficina Económica del Presidente (2006:1), este elevado crecimiento ha venido acompañado por un intenso ritmo de creación de empleo (a un ritmo medio anual de más de 600 mil personas desde 1996), un notable crecimiento de la población activa, (la tasa de actividad total de la economía se elevó en el año 2006 hasta más del $70 \%$ desde $61,5 \%$ en 1996) y una gran reducción del paro (del 20\% en 1996 hasta el 8,6\% en el cuarto trimestre de 2007).

${ }^{14}$ Recordemos que hay seis regímenes diferentes de cotización a la seguridad social. El régimen general es el que agrupa a los trabajadores asalariados de la mayor parte de los sectores, sean de la industria, la construcción o de servicios; los otros cinco son regímenes especiales: el de trabajadores autónomos, el agrario, el de trabajadores del mar, el de trabajadores de la minería y el carbón, así como el de empleados del hogar. 
General de la Seguridad Social. ${ }^{15}$ En ésta puede verse que el grupo más numeroso son los peones en la mayoría de los grupos nacionales, excepto en el caso de los argentinos y cubanos que tienen una distribución por categorías que difiere bastante de la del resto de los inmigrantes y, en cambio, se asemeja más a la de españoles. En la misma tabla se observa que los colectivos con porcentajes altos de peones son el boliviano (37.2\%), el ecuatoriano (36.5\%) y el dominicano (30.6\%). Casi todos los colectivos tienen los mayores porcentajes en oficiales de tercera, de primera y de segunda, aunque también presentan proporciones relativamente elevadas en la categoría de auxiliares administrativos (generalmente ocupados por mujeres). Por encima de esas categorías, la participación es muy baja, especialmente cuando los comparamos con los de los afiliados españoles que se muestran en la última línea. La excepción es, como señalábamos antes, la distribución de los argentinos y los cubanos.

Por último, algunas cuestiones referidas a la movilidad laboral, en este caso estimada a través del saldo entre la categoría ocupacional del migrante en el último empleo en su país de origen y el empleo "actual" (en el momento de la encuesta, ENI 2007). De este modo se puede observar que el $45 \%$ de los trabajadores latinoamericanos se mantuvo en la misma categoría ocupacional que tenía antes de emigrar, 44\% descendió y 11\% experimentó una movilidad ascendente. Por tanto, considerando el conjunto de trabajadores de origen latinoamericanos en España, el proceso migratorio agravó las condiciones de trabajo con respecto al país de origen. Como sugiere Actis (2009:81), esta constatación conduce a medir la movilidad en términos de salarios percibidos antes y después de la migración. Siguiendo al autor la remuneración media de los latinoamericanos en 2006 era de 1.038 euros (1.242 para los hombres y 837 para las mujeres), un valor inferior a la media de los trabajadores españoles (1.677 euros). Sin embargo, si se compara este valor con el vigente en los países de origen, se verifica una superioridad innegable que explica, en parte, la vigencia del proyecto migratorio.

Tabla VII. España. Latinoamericanos en alta laboral en la Seguridad Social (Régimen General y de la minería y del Carbón) por nacionalidad (destacando los países con mayor número de residentes) y categoría laboral, a 31 de3 diciembre de 2008 (Porcentajes horizontales)

\begin{tabular}{|c|c|c|c|c|c|c|c|c|c|c|}
\hline & 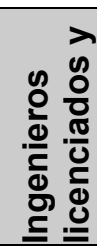 & 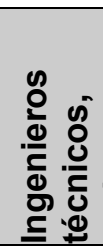 & 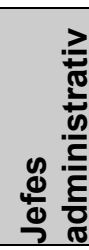 & 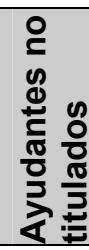 & 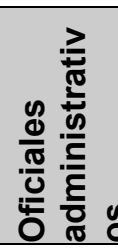 & 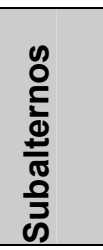 & 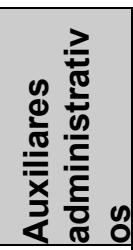 & 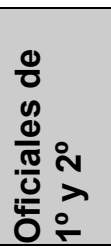 & 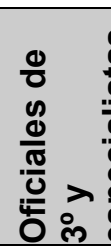 & 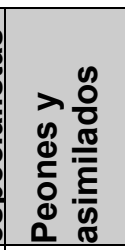 \\
\hline & $7.3 \%$ & $2.0 \%$ & $3.3 \%$ & $3.1 \%$ & $11.3 \%$ & $3.7 \%$ & $16.0 \%$ & $21.5 \%$ & $16.3 \%$ & $15.5 \%$ \\
\hline Boli & $.4 \%$ & $0.3 \%$ & $0.5 \%$ & $1.4 \%$ & $3.1 \%$ & $4.7 \%$ & $9.5 \%$ & 22. & $19.7 \%$ & $37.2 \%$ \\
\hline Colc & $.7 \%$ & $1.3 \%$ & $.2 \%$ & $1.9 \%$ & & $4.7 \%$ & $12.8 \%$ & & $20.7 \%$ & $28.8 \%$ \\
\hline & & $2.2 \%$ & $2.2 \%$ & $2.4 \%$ & $8.5 \%$ & $5.1 \%$ & & & $19.3 \%$ & $18.4 \%$ \\
\hline Ecuador & $.4 \%$ & $0.2 \%$ & $0.4 \%$ & $1.3 \%$ & $3.7 \%$ & $4.0 \%$ & $10.6 \%$ & $22.5 \%$ & $20.5 \%$ & $36.5 \%$ \\
\hline
\end{tabular}

${ }^{15}$ Cabe advertir al lector que la clasificación por grupos de cotización sólo se refiere al régimen general, por lo tanto no están incluidas las empleadas del servicio doméstico ni los peones agrícolas que cotizan en sus propios regímenes, como se ha visto en la Tabla VI. 


\begin{tabular}{|l|c|c|c|c|c|c|c|c|c|c|}
\hline Perú & $2.8 \%$ & $1.4 \%$ & $1.7 \%$ & $1.7 \%$ & $6.1 \%$ & $7.3 \%$ & $13.9 \%$ & $16.9 \%$ & $22.5 \%$ & $25.7 \%$ \\
\hline $\begin{array}{l}\text { R. } \\
\text { Dominicana }\end{array}$ & $1.4 \%$ & $0.2 \%$ & $0.7 \%$ & $1.7 \%$ & $5.5 \%$ & $4.3 \%$ & $10.2 \%$ & $17.5 \%$ & $17.8 \%$ & $30.6 \%$ \\
\hline $\begin{array}{l}\text { Total } \\
\text { extranjeros }\end{array}$ & $4.3 \%$ & $1.7 \%$ & $2.0 \%$ & $1.9 \%$ & $6.5 \%$ & $3.8 \%$ & $10.1 \%$ & $22.6 \%$ & $19.6 \%$ & $27.7 \%$ \\
\hline $\begin{array}{l}\text { Total } \\
\text { españoles }\end{array}$ & $9.1 \%$ & $7.7 \%$ & $5.0 \%$ & $3.9 \%$ & $13.9 \%$ & $4.8 \%$ & $13.9 \%$ & $18.8 \%$ & $10.2 \%$ & $12.4 \%$ \\
\hline
\end{tabular}

Fuente: elaboración propia con datos del OPI (2009); MTI (2008)

\section{Conclusiones}

La emigración internacional de latinoamericanos y caribeños se ha incrementado significativamente en las dos últimas décadas debido a un agravamiento de la situación económica y social en la región, a partir de la aplicación de modelos de desarrollo neoliberales. Una parte significativa de los flujos se ha dirigido a nuevos destinos migratorios distintos a Estados Unidos, entre los que se encuentra España como el más dinámico. Esta migración incluye a otros países de la OCDE (Italia, Países Bajos, Reino Unido, Francia y Portugal) y procede, en gran parte, de antiguas colonias. Estas características permiten suponer que se encuadra dentro de un sistema migratorio SUR-Norte en el cual los desplazamientos humanos son parte de fluidos intercambios históricos de población (antes en dirección contraria). Y allí donde los hombres, van también van sus ideas (cultura), creencias (religión), formas de organizarse para la satisfacción de necesidades (economía) y para la resolución de conflictos derivadas de esta (política).

El análisis de fuentes estadísticas ha permitido observar que la mayor parte de la inmigración latinoamericana y caribeña $(79,9 \%)$ llegó a España durante la última década, dejando un saldo de más de dos millones de personas. Esta migración "aluvional" tuvo temporalidades diferentes de acuerdo a los contingentes nacionales involucrados, pero en general estuvo protagonizada por personas procedentes de Sudamérica. Un proceso que aún presenta cierto dinamismo en los casos de Bolivia y Paraguay, pero con volúmenes más reducidos que en la década anterior. Además, en los últimos años se ha abierto una nueva fase de inmigración de centroamericanos y caribeños oriundos de Nicaragua, Honduras, El Salvador y Guatemala.

Sin embargo, el análisis también ha detectado que esta migración no es nueva. Tan temprano como 1970 ya existía un pequeño núcleo de inmigrantes (51.191 personas), principalmente argentinos (27\%), cubanos (36\%) y venezolanos (33\%). Por tanto, este sistema migratorio no comenzó desde cero sino que ya se encontraba en estado embrionario en la década de 1970, y fue creciendo paulatinamente durante los años '80 y '90 para "despegar" en la década siguiente. Esta raíz histórica no hace más que confirmar que ni bien se detuvieron las migraciones de españoles hacia América, comenzaron las de americanos hacia España. Un indicio más para pensar en un sistema migratorio iberoamericano en el existen fluidos intercambios de población en uno y otro sentido según coyunturas nacionales. 
Con todo, la actual crisis económica internacional plantea diversos interrogantes respecto al futuro de este sistema migratorio. Por un lado, podría suponer la detención de los flujos debido a medidas más proteccionistas desarrolladas por España, e incluso la posibilidad de retornos significativos ante la destrucción de puestos de trabajo y la extensión de la pobreza entre los inmigrantes. Por otro, la extensión de la crisis a Latinoamérica y el Caribe podría motivar nuevos flujos a partir de la activación de cadenas migratorias con las diásporas ya asentadas en España. Finalmente, podrían aparecer nuevos destinos, intra o extra regionales, que amplíe aún más el sistema migratorio. Estas cuestiones platean un futuro abierto, pero a la vez poco alentador.

\section{Bibliografía}

(2009) ACTIS, Walter. Inmigrantes latinoamericanos en España: una visión de conjunto. Migraçoes, $n^{\circ} 4$, Observatorio da Inmigraçao, Lisboa, en prensa.

(2008) ACTIS, W.; ESTEBAN, F. O. "Argentinos en España: inmigrantes a pesar de todo". En Migraciones, 23, 79-115.

(1999) CASTEL, Robert. Les métamorphoses de la question sociale, Paris:

Gallimard

(1992) CAVAROZZI, Marcelo. "Beyond Transitions to Democracy in Latin America". Journal of Latin American Studies 24 (3): 65-84

(2007) DELGADO, LOLA; LOZANO, Daniel. Latinos en España. Cómo son y cómo viven colombianos, argentinos, ecuatorianos, venezolanos... Madrid: La Esfera de los Libros

(1995) GARCÍA CANCLINI, Néstor. Consumidores y ciudadanos: Conflictos multiculturales de la globalización. México: Grijalbo.

(1978) GERMANI, GINO. Authoritarianism, Fascism, and National Populism. New Jersey: Transaction Books.

(2007) GÓMEZ CIRIANO, Emilio, J. Ecuatorianos en España: claves de un proceso migratorio en cuatro tiempos. En Gómez Ciriano, Emilio, J.; Tornos Cubillo, Andrés; Colectivo IOE, Ecuatorianos en España. Una aproximación sociológica. Madrid: Ministario de Trabajo y Asuntos Sociales

(2002) GONZÁLEZ YANCI, Ma Pilar; AGUILERA ARILLA, José Ma. " La inmigración cubana en España. Razones políticas y de sangre en la elección del destino". En Espacio, tiempo y forma. Serie VI, Geografía, pp.11-27

INE (Instituto Nacional de Estadística). Explotación Estadística del Padrón de Habitantes. En Demografía y Población, Cifras de Población y Censos 
Demográficos [En Línea] Madrid, Varios años. [Ref. de 14-12-2008] Accesible en Internet: http://www.ine.es>

(2007) Encuesta Nacional de Inmigrantes. Demografía y Población, Migraciones [En Línea] Madrid, Mayo de 2008. [Ref. de 14-12-2008] Accesible en Internet: http://www.ine.es

(1992) KRITZ, M. M.; ZLOTNIK, H. "Global interactions: migration system, processes, and policies". En KRITZ, M., M.; LIM, LEAN, L.; ZLOTNIK, H. International migration systems. A global approach. Oxford: Claredon Press, pp. $1-15$.

(2008) MAGUID, Alicia M.; MARTÍNEZ, Rosana. "La emigración reciente de sudamericanos a Estados Unidos y a España: el caso de los argentinos". Trabajo presentado en el III Congreso de la Asociación Latinoamericana de Población, ALAP, realizado en Córdoba, Argentina, del 24 al 26 de Septiembre de 2008.

(2004) MARTÍNEZ PIZARRO, Jorge. "Tendencias recientes de la migración internacional en América Latina y el Caribe". Estudios Migratorios Latinoamericanos, año 18, 54, 211-239.

(2008) (ED). América Latina y el Caribe: migración internacional, derechos humanos y desarrollo. Santiago de Chile: CEPAL

(1994) MASSEY, Douglas, et al. "An evaluation of international migration theory: The North America case". Population and Development Review, 20(4), 699-751.

(1970) MOBOGUNJE, Akin, L. "System approach to a theory of rural - urban migration". En Geographical Analysis, 2, 1-18.

(2008) Ministerio de Trabajo e Inmigración (MTI). Boletín de Estadísticas Laborales. Diciembre. Madrid: Subsecretaría de Trabajo e Inmigración, MTI.

(2008) MORALES MENA, Natalia. "Uruguay como país de partida, Uruguay como destino: análisis de cambios y continuidades en la migración uruguaya. Scripta Nova. Revista Electrónica de Geografía y Ciencias Sociales, Vol. XII, no 279, (on line) Disponible en http://www.ub.es/geocrit/sn/sn-279.htm [Referencia de 10-08-2009]

(2010) NACIONES UNIDAS. Department of Economic and Social Affairs, Population Division (2009). Trends in International Migrant Stock: The 2008 Revision (United Nations database, POP/DB/MIG/Stock/Rev.2008).

(2008) OECD. Statistical Annex, Internacional Migration Data 2007. [En línea]. Paris: OECD. (Obtenido el 20/11/2008) Disponible en:

http://www.oecd.org/dataoecd/16/31/39681765.pdf

(2010) OECD. International Migration Database. [En línea] París: OECD (Obtenido el 04/05/2010) Disponible: http://stats.oecd.org

Varios años. Observatorio Permanente de la Inmigración (opi). Anuario Estadístico de Extranjería, Disponible en

http://extranjeros.mtin.es/es/InformacionEstadistica/index.html [Referencia de 10-11-2010]

(2006) Oficina Económica del Presidente. Inmigración y economía española: 1996-2006, Presidencia del Gobierno

(2003) PELLEGRINO, Adela. "La Migración Internacional en América Latina y el Caribe: tendencias y perfiles de los migrantes". Serie Población y Desarrollo $N^{\circ}$ 35, CELADE-CEPAL. Santiago de Chile: CELADE-CEPAL, BID, marzo de 2003. 
(2004) PELLEGRINO, Adela. "Migration from latin America to Europe: Trends and

Policy Changes". OIM, International Organization for Migration.

(2004) PNUD (Programa de la Naciones Unidas para el Desarrollo). La democracia en América Latina. Hacia una democracia de ciudadanos y ciudadanas. Buenos Aires: Aguilar, Altea, Taurus, Alfaguara.

(2003) ROMERO VALIENTE, Juaqn Manuel. "La migración dominicana hacia España, factores, evolución y desarrollo", Revue européenne des migrations internationales [En ligne], vol. 19 - n¹ (Referencia de 10-08-2009) http:// remi.revues.org/index387.html

(1992) SÁNCHEZ ALONSO, Blanca. La inmigración española en Argentina. Siglos XIX y XX. Columbres (Asturias): Ediciones Juncar, Archivo de Indianos (2003) SOLIMANO, Andrés. "Globalización y migración internacional: la experiencia latinoamericana", Revista de la CEPAL 80, 55-72

(1989) TOURAINE, Alain. La parole et le sang. Paris: Odile Jacob

(2004) WEYLAND, Kurt Gerhard. "Neoliberalism and Democracy in Latin America: A Mixed Record", Latin American Politics and Society vol. 46 (1): 135159. 